\title{
Exposure to catastrophe risk and use of reinsurance: an empirical evaluation for the U.S.
}

\author{
Alejandro Drexler ${ }^{1} \cdot$ Richard Rosen $^{1}$
}

Received: 2 May 2019 / Accepted: 27 January 2020 / Published online: 7 September 2020

(C) The Author(s) 2020

\begin{abstract}
Reinsurance has long been used for tail risk protection. There is ample anecdotal information from practitioners about this dimension of reinsurance. The subject, however, remains largely unexplored in the academic literature given the lack of data about non-proportional reinsurance contracts. We develop a novel approach to measure the use of non-proportional reinsurance and use it to disentangle reinsurance used for catastrophe risk protection from reinsurance used for other motivations, for example regulatory capital relief. Our findings rely on a new measure of catastrophe risk that has strong explanatory power about insurers' behaviour towards risk beyond what has been captured by existing measures.
\end{abstract}

Keywords Reinsurance $\cdot$ Catastrophe losses · Tail risk

\section{Introduction}

Property and casualty (P\&C) insurers seldom go broke. This is surprising in an industry frequently buffeted by large unpredictable losses. For example, in 2005, when three of the 10 most devastating hurricanes in U.S. history occurred, only two insurers shut their doors despite insured catastrophe losses of USD 100 billion. These losses were not only three times larger than the average yearly losses from catastrophes, but represented $25 \%$ of the industry's capital heading into 2005 (Munich Re 2017). In this paper, we present evidence on how P\&C insurers use reinsurance to mitigate the effects of such large losses. Although theoretical models show that using reinsurance to cover tail events, such as hurricanes, can be the optimal choice for utility-maximising insurers (Vajda 1962; Borch 1962), few have studied this issue. This is in part due to the difficulty of measuring exposure to

Alejandro Drexler

alejandro.h.drexler@chi.frb.org

Richard Rosen

Richard.rosen@chi.frb.org

1 Federal Reserve Bank of Chicago, 230 S LaSalle, Chicago, IL 60604, USA 
catastrophes and in part due to the difficulty of measuring the share of reinsurance tailored to addressing catastrophe (CAT) risks (Engeström 1995). To examine the use of reinsurance for CAT risk, we introduce both a new measure of CAT risk and a new measure of the share of reinsurance that provides tail protection.

Insurers pool many insurance policies and care mostly about the net risk from the policies in a pool. To the extent that the risks of the different policies in a pool are idiosyncratic (uncorrelated), there are diversification benefits from pooling. In most circumstances, the accident-related damages that any two auto policyholders may suffer are largely uncorrelated. This is why the losses of a large pool of auto policies can be predicted with some accuracy. However, there are risks that are systematic - that is, common across policies. One example of this would be the damage to cars from a hurricane. Such risks would hit many auto policies at the same time. These events may be harder to accurately predict and may not be as easy to diversify. These systematic, hard-to-diversify risks are the focus of this paper. ${ }^{1}$ By convention, we refer to them as CAT risks. In the paper, we introduce a new measure of the CAT risk faced by insurers and use it to study the use of reinsurance.

Reinsurance is insurance for insurers, and insurers use it to reduce their exposure to risk. There is a large volume of literature showing that among the reasons insurers have for wanting to use reinsurance, the most common is that they are risk averse (see, e.g. Borch 1961; Raviv 1979; Doherty and Schlesinger 1983; Mayers and Smith 1990; Cummins et al. 2002; Wang et al. 2005; Huang 2006). In essence, reinsurance allows insurers to improve diversification by pooling risks across companies. For example, an insurer based in Florida will have trouble diversifying its risk from hurricanes. However, a reinsurer that absorbs some of the hurricane risk from the Florida insurer can pool it with hurricane risks from insurers in other states and other CAT risks from insurers, whether in the U.S. or elsewhere. This allows diversification above that available to the Florida insurer. In 2013, USD 100 billion of U.S. insurance premiums were ceded with USD 60 billion ceded to U.S.-based reinsurers and USD 40 billion to non-U.S.-based reinsurers (Polacek 2015).

Reinsurance mainly comes in two forms: quota (proportional) contracts and nonproportional contracts. In quota contracts, the insurer transfers a fixed proportion of premiums to the reinsurer. In exchange, the reinsurer covers the same proportion of losses. In a non-proportional contract, the proportion of losses covered by the reinsurer is generally higher when the insurer experiences larger losses. While insurers often have a combination of quota and non-proportional reinsurance, non-proportional contracts are more tailored to mitigating the effects of CAT risk. In 2013, an estimated $25 \%$ of the payments from insurers to U.S.-based reinsurers were for nonproportional agreements (Polacek 2015).

Exposure to CAT risk, which we expect to be an important driver of the use of reinsurance, is difficult to measure. One way to measure exposure is to proxy for CAT risk using insurer characteristics thought to be related to higher catastrophic

\footnotetext{
1 Since we use historical data, our analysis may say more about the use of reinsurance against natural catastrophes than the use of reinsurance for such things as cyber events or man-made disasters since there are very few of these latter types of events in the data.
} 
events, such as exposure to coastal states (Powell and Sommer 2007). Since coastal states have been historically more prone to suffer from catastrophic events, it is reasonable to believe that insurers with more business in those states will be more likely to be affected by CAT shocks, all else being equal. Indeed, there is significant correlation between exposure to coastal states and the use of reinsurance (Powell and Sommer 2007); the use of reinsurance is higher in regions prone to large catastrophes (Drexler and Nekoul 2016). Other insurer characteristics that have been explored as drivers of reinsurance include line of business concentration, number of subsidiaries and ownership structure (Mayers and Smith 1990; Powell and Sommer 2007; Wang et al. 2008). While these variables are not directly related to the likelihood of suffering CAT events, they affect the ability of insurers to diversify the losses associated with these events.

We introduce a measure of CAT risk that uses the information about an insurer's risk exposure found in the pattern of losses taken by the insurer. Loosely speaking, insurers that occasionally experience large losses relative to their baseline losses are likely more exposed to CAT risk than those that do not. ${ }^{2}$ To formalise this, we define the risk exposure for an insurer in a year to be the largest gross loss ratio in the prior 10 years normalised by the average gross loss ratio in the prior 10 years, where the gross loss ratio for an insurer is its ratio of direct losses to direct premiums. ${ }^{3} \mathrm{We}$ call this measure loss-based catastrophe risk exposure or loss-based CRE.

The main goal of this paper is to explore the extent to which insurers use nonproportional reinsurance to cope with CAT risk. Because insurers only report aggregate reinsurance, prior studies on the subject have not examined non-proportional reinsurance separately. ${ }^{4}$ By developing a measure of the quota-non-proportional split, we are able to focus more tightly on our main goal. Payments from reinsurance in low-loss years are used to estimate the share of reinsurance that is quota, with the remainder being non-proportional. We estimate that roughly one third of reinsurance by the value of premiums ceded is non-proportional, qualitatively similar to earlier estimates (Polacek 2015). ${ }^{5}$

Analysing quota and non-proportional reinsurance separately shows the importance of a tightly-defined CAT risk exposure measure. We find that insurers with a larger loss-based CRE use more non-proportional reinsurance, all else being equal. We also find that, even after controlling for the existing measures of CAT risk, a one standard deviation increase in our measure predicts that three

\footnotetext{
2 There are other reasons why an insurer might have large losses in a year, including insufficient pricing (as in the case of long-term care, see Mohey-Deen and Rosen 2018) or poor claims handling. We think that these are rarely responsible for the large losses we use to set our risk exposure measure (long-term care insurance is not in our sample). However, to the extent that non-CAT losses occasionally drive our risk exposure measure, this adds noise to our estimates of the use of non-proportional reinsurance.

3 We normalise by the average loss ratio because insurers might differ in their largest loss ratio for reasons other than CAT exposure; for example, differences in product mix.

${ }^{4}$ U.S. reinsurers are required to report the total premiums assumed through non-proportional reinsurance contracts and the total premiums assumed through quota contracts (Polacek 2015). However, they are not required to disaggregate this information by ceding insurer.

5 The small differences between our estimates and Polacek's may reflect differences in our sample period (2007-2018) compared to his (2004-2013), as well as the use of different techniques.
} 
percentage points more of premiums will be reinsured using non-proportional contracts (a one-third increase in non-proportional reinsurance), with no significant impact on quota reinsurance. However, while exposure to coastal states, as measured in other studies (Powell and Sommer 2007), leads to more overall reinsurance use, it doesn't affect the use of non-proportional reinsurance, all else being equal. When we look deeper into this, it appears that this may be because of the coarseness of the coastal state exposure measure. The measure mixes states where CAT exposure is statewide (e.g. Florida) with states where only a small share of insurers likely face major CAT risk (e.g. New York). Consistent with this explanation, we find that greater exposure where CAT risk is widespread (Florida and earthquake insurance in California) leads to increased use of nonproportional reinsurance, but greater exposure to other states (such as New York) does not increase the use of non-proportional reinsurance.

Splitting reinsurance usage into quota and non-proportional also allows us to shed light on other drivers of the use of reinsurance. Prior studies have suggested that reinsurance usage responds to factors that lead insurers to be risk averse, such as the probability of bankruptcy, the ability to use reinsurance to do tax or capital arbitrage and the direct benefits of reinsurance such as the availability of real services (e.g. Mayers and Smith 1990; Garven and Lamm-Tennant 2003; Koijen and Yogo 2016). We expect that some of these factors, such as bankruptcy avoidance, are easier with non-proportional reinsurance, while others, such as capital arbitrage, can be accomplished with quota reinsurance. Prior studies have been unable to identify which factors drive the use of each type of reinsurance because they do not separate non-proportional and quota reinsurance. Reinsurance can reduce the amount of regulatory capital an insurer is required to hold (for a particular case, see Koijen and Yogo 2016). It can also reduce the chance of insolvency for a highly levered insurer (Garven and Lamm-Tennant 2003). Both of these are of benefit for low-capital insurers. We show that low-capital insurers are more likely to use quota rather than non-proportional reinsurance. According to our estimations, insurers in the bottom quartile of the risk-based capital (RBC) ratio after reinsurance use $11.3 \%$ more quota reinsurance than insurers in the top quartile. However, the RBC ratio has no significant effect on the use of non-proportional reinsurance. This is consistent with evidence provided by practitioners and regulators indicating reinsurance products offered to relieve regulatory capital needs rely mostly on quota agreements (Zhou-Richter and Kuschel 2012; Wertli 2016; Troutman 2011; Lum 2013). Also, when the RBC ratio is used as a control, we find that leverage has no effect on the use of reinsurance.

Reinsurance allows insurers to benefit from the expertise of reinsurers. Access to reinsurers' expertise might be less necessary for specialised firms who, because they concentrate their activities, may know more about their specialty than reinsurers (Mayers and Smith 1990). All else being equal, there is weak evidence to suggest that insurers that are more specialised, as measured by having a larger business line or geographic concentration, use less reinsurance.

Our study contributes to an open discussion about the use of tail risk reinsurance. As noted earlier, empirical work exploring tail reinsurance is scant. One approach to understanding this question is provided in Froot (2001), which explores how 
reinsurance contracts are structured within an insurer. We add to this discussion by studying the drivers of variation in the use of reinsurance between insurers.

\section{Data}

We examine CAT risk exposure at P\&C insurance companies operating in the U.S. ${ }^{6}$ The data come from annual regulatory reports filed with state insurance commissioners and are provided by S\&P Global Market Intelligence.

Regulatory reports are filed by insurers at the operating company level; similarly, reinsurance agreements are also signed at the company level. Many insurance companies are part of larger groups, where a group is defined as a set of companies under the same ownership. For these companies, we aggregate data to the group level for our analysis under the maintained hypothesis that risk decisions are made at the aggregate level. ${ }^{7,8}$ Henceforth, when we refer to an insurance company or insurer we mean the aggregation of $\mathrm{P} \& \mathrm{C}$ companies within a group.

Insurers can obtain reinsurance from affiliated companies within their group or from non-affiliated companies. Because we work under the hypothesis that risk decisions are made at the aggregate level, we only consider reinsurance from non-affiliates in the analysis.

Our analysis focuses on groups that provide insurance to policyholders rather than groups that offer reinsurance to other insurers. However, many insurance groups, especially large ones, often offer small amounts of reinsurance to other groups - or, more formally, assume premiums from insurers in other groups. Therefore, there is no clear distinction between insurance companies and reinsurance companies. To focus on the reinsurance decisions of groups that primarily provide insurance to policyholders, we drop all groups where the ratio of premiums assumed from other insurers, including fronting (i.e. insurance provided to other insurers), to the insurance provided directly to policyholders is larger than $20 \%$. The results are robust to drawing the line at a different percentage.

\footnotetext{
${ }^{6}$ We include all types of CAT losses. However, as mentioned earlier, man-made and cyber risk events are infrequent compared with natural catastrophes. Therefore, our results are likely driven by natural catastrophe risk.

${ }^{7}$ One caveat to this approach is that companies are regulated at the state level and state regulators can impose restrictions on the extent to which operating companies can transfer funds to other companies within the same group. In the presence of these restrictions, the risk of an individual operating company, as well as the amount and type of reinsurance agreements it engages in, might have real effects on the group's capital allocation and, ultimately, on the group's performance. However, since instances where an insurance company fails while the rest of its group remains well capitalised are rare, we find it appropriate to conduct our analysis at the group level. Also, at the time of writing, U.S. insurers did not face group-level capital requirements. Insurers designated as systemically important will eventually have group-level capital requirements, but these were not in place during our sample period and, even if implemented, will not exempt insurers from state-level requirements.

${ }^{8}$ We aggregate data for the U.S. P\&C operating companies within a group, netting out reinsurance among insurers within a group. One limitation of our data is that we do not have data on non-U.S. operating companies within groups headquartered in the U.S.
} 
The sample includes only insurers with at least nine years of data. This is because our measure of CAT risk exposure is based on historical data and we require that an insurer have at least eight years of data to derive the CAT risk proxy. We drop insurers with negative losses, premiums or reinsurance amounts. ${ }^{9}$ After imposing these restrictions, our sample consists of 478 groups operating from 2007 to 2018, of which 250 are standalones. For simplicity, we exclude non-P\&C operations from the analysis. Panel A of Table 1 gives the summary statistics for the sample. On average, an insurer in our sample had USD 4.1 billion in assets and wrote USD 1.4 billion in premiums in a typical year. However, there is wide disparity in the size of insurers. The median asset size and yearly premiums in the sample are USD 336 million and USD 140 million, respectively.

The data are structured as a panel of insurance groups. However, the variable of interest, 'risk exposure', has very limited variation within an insurer. Therefore, we run the statistical analysis without fixed effects and results arise from differences between insurers. To reduce concerns of endogeneity we include an ample set of variables that control for insurers' characteristics affecting reinsurance decisions. Standard errors are clustered at the insurer level.

\section{Methodology}

Insurers use reinsurance for different reasons. Two broad themes capture many of these. First, through non-proportional reinsurance, an insurer can transfer some tail risks to a reinsurer. Second, through quota reinsurance insurers share the risk (tail and non-tail) from a policy with a reinsurer, reducing the capital that is required to mitigate the possibility of the insurer running out of funds to pay claims. We examine how insurer characteristics affect the use of reinsurance.

We are particularly interested in the role catastrophe risk exposure might play in explaining the use of reinsurance; therefore, we centre our analysis on this dimension. A challenge in understanding the effect of CAT risk exposure on reinsurance is that risk exposure is not observable. In the extant literature, risk exposure has been quantified using insurers' characteristics that are thought to affect exposure to this risk. These characteristics include percentage of business in states that are more exposed to catastrophes, geographic concentration and business line concentration.

Hurricane losses tend to be larger in states on the east coast and in states that border the Gulf of Mexico (Drexler and Nekoul 2016) while earthquake losses tend to be largest in California. Consistent with this evidence, studies have used premiums written in these areas as a proxy for CAT risk. We use one particular measure from the literature in which CAT risk was measured by the ratio of the sum of premiums written by an insurer in east coast and Gulf states plus earthquake premiums written in California to the total premiums written by the insurer (e.g. Powell and Sommer 2007). This measure, which we call geographic CRE, varies widely across insurers.

9 The results are robust to excluding companies with less than 20 years of history

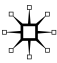


In our data, it averages $38.7 \%$ (Table 1), with $28.2 \%$ of insurers having no exposure to coastal states and also writing no earthquake insurance in California. Other papers measure CAT risk exposure using different combinations of states and types of policies (e.g. Mankai and Belgacem (2016) use east coast states and earthquake insurance while Park and Xie (2014) use a different collection of southern states and focus on lines more subject to CAT risk). Our results are not especially sensitive to the geographically-based CAT risk measure we use.

The ability of an insurer to bear the losses from a catastrophic event may also depend on how diversified the insurer is, either geographically or across business lines. Studies that have examined the effects of diversification on the use of reinsurance used measures of concentration calculated similarly to the Herfindahl measure of market concentration. Geographic Herf is estimated as the sum of squared proportions of premiums written in each state, and business line Herf is defined similarly across business lines (Mayers and Smith 1990). ${ }^{10}$ The presumption is that, all else being equal, less concentrated (that is, more diversified) insurers have less need to use reinsurance against CAT events. However, there is a complication - it is not clear that, in general, the all-else-being-equal assumption holds. Reinsurers provide risk relief, but they can also provide information to insurers, if by no other means than setting a price for the reinsurance. Concentrated insurers may have less need for reinsurers' information (this is part of what Mayers and Smith (1990) refer to as real service efficiencies). Thus, the net effect of concentration on insurers' incentives to use reinsurance trades off lack of diversification (and CAT risk exposure) against specialisation. Not surprisingly, both geographic and business line concentration vary significantly across insurers (see Table 1 ).

Location and concentration measures are coarse estimates of CAT risk exposure. The public insurance data, such as those we use, is aggregated to the state level for each insurer. This can make it difficult to separate out insurers that are very exposed to CAT risk from those that are less exposed. Take the state of New York as an example. CAT risk is much larger for policies for residents and businesses in Long Island compared to similar policies in upstate New York. Because the data for insurers in New York is at the state level, there is no direct way to determine which insurers in the state write policies primarily on Long Island and which write policies primarily upstate.

We propose an alternative measure of CAT risk exposure based on actual loss experience. The operating assumption is that insurers that have had extreme loss events in the past are more subject to CAT risk. Loss-based CAT risk exposure for insurer $i$ in year $t$ is defined as

$$
\text { Loss-based } C R E_{i, t} \equiv \frac{\max _{(t-9) \leq s \leq t}\left(\text { loss ratio }_{i, s}\right)}{\begin{array}{l}
\text { average } \\
(t-9) \leq s \leq t
\end{array}}
$$

\footnotetext{
10 Specifically, business line concentration is defined as the sum of squared proportions of premiums written in each of 27 different insurance lines of business.
} 
Table 1 Variables used in the paper

Panel A: Summary statistics

\begin{tabular}{llllll}
\hline & Mean & St. dev. & p25 & p50 & p75 \\
\hline Assets & 4.061 & 15.426 & 0.071 & 0.336 & 1.548 \\
Total premiums & 1.351 & 4.907 & 0.035 & 0.140 & 0.580 \\
Share of premiums reinsured & 0.325 & 0.203 & 0.156 & 0.303 & 0.468 \\
Loss ratio & 0.543 & 0.183 & 0.448 & 0.546 & 0.632 \\
Share of losses reinsured & 0.322 & 0.219 & 0.135 & 0.310 & 0.475 \\
Non-proportional share & 0.102 & 0.100 & 0.032 & 0.071 & 0.138 \\
Quota share & 0.223 & 0.206 & 0.048 & 0.155 & 0.379 \\
Loss-based CRE & 1.459 & 0.480 & 1.201 & 1.310 & 1.516 \\
Geographic CRE & 0.387 & 0.377 & 0.000 & 0.304 & 0.762 \\
Geographic Herf & 0.495 & 0.380 & 0.110 & 0.411 & 1.000 \\
Business line Herf & 0.532 & 0.249 & 0.335 & 0.440 & 0.698 \\
RBC ratio & 10.323 & 5.407 & 6.637 & 9.208 & 12.656 \\
AM Best rating & 3.805 & 1.446 & 3.000 & 4.000 & 4.000 \\
AM Best high & 2.689 & 0.544 & 2.000 & 3.000 & 3.000 \\
AM Best medium & 4.000 & 0.000 & 4.000 & 4.000 & 4.000 \\
AM Best low & 5.864 & 1.241 & 5.000 & 5.000 & 6.000 \\
Return on assets & 0.070 & 0.121 & 0.020 & 0.070 & 0.126 \\
Leverage & 1.380 & 0.881 & 0.843 & 1.240 & 1.699 \\
Premiums/adjusted capital & 1.165 & 0.953 & 0.655 & 0.973 & 1.413 \\
Insurer is part of a group & 0.575 & 0.494 & 0.000 & 1.000 & 1.000 \\
Stock company & 0.624 & 0.485 & 0.000 & 1.000 & 1.000 \\
\hline Panel B: & & & & &
\end{tabular}

Panel B: variable definitions ${ }^{\mathrm{a}}$

Name Definition

Assets

Total premiums

Share of premiums reinsured

Loss ratio

Share of losses reinsured

Non-proportional share

Quota share

Loss-based CRE

Geographic CRE

Geographic Herf

Business line Herf
Assets as reported by the insurer to the state insurance commissioner

Premiums associated with policies issued directly by the insurer to policyholders

Ratio of premiums ceded to reinsurers (or to other insurers acting as reinsurers) to total premiums plus assumed premiums ${ }^{\mathrm{b}}$

Ratio of total losses to total premiums ${ }^{\mathrm{c}}$

Ratio of losses ceded to reinsurers (or to other insurers acting as reinsurers) to direct losses plus assumed losses

Share of premiums ceded to non-proportional reinsurance contracts ${ }^{\mathrm{d}}$

Share of premiums ceded to proportional reinsurance contracts ${ }^{\mathrm{e}}$

Exposure to catastrophe risk based on historical losses. Calculated as the maximum value of the loss ratio within the last 10 years divided by the average value of the loss ratio within the last 10 years

Exposure to catastrophe risk based on geographic location. Calculated as the share of all premiums at an insurer that is issued in Atlantic and Gulf states plus earthquake premiums issued in California

Sum of the squared proportion of premiums written in each state

Sum of the squared proportion of premiums written in each business line 
Table 1 (continued)

Panel B: variable definitions ${ }^{\mathrm{a}}$

\begin{tabular}{|c|c|}
\hline Name & Definition \\
\hline $\mathrm{RBC}$ ratio & Adjusted capital over RBC capital $^{\mathrm{f}}$ \\
\hline AM Best rating & $\begin{array}{l}\text { Correlative number from } 1 \text { to } 15 \text { where } 1 \text { represents an } \mathrm{AM} \text { Best rating } \\
\text { of } \mathrm{A}++ \text { (best rating) and } 15 \text { represents an AM Best rating of } \mathrm{F} \text { (worst } \\
\text { rating) }\end{array}$ \\
\hline AM Best high & AM Best rating of $\mathrm{A}$ or better \\
\hline AM Best medium & AM Best rating of A- \\
\hline AM Best low & $\mathrm{AM}$ Best rating of $\mathrm{B}++$ or worse \\
\hline Return on assets (ROA) & Pre-tax income divided by assets \\
\hline Leverage & Liabilities divided by adjusted capital \\
\hline Premiums/adjusted capital & Total premiums divided by adjusted capital \\
\hline Insurer is part of a group & $\begin{array}{l}\text { Dummy variable that takes the value of } 1 \text { if the insurer is part of a hold- } \\
\text { ing company owning more than } 1 \text { insurer and } 0 \text { otherwise }\end{array}$ \\
\hline Stock company & $\begin{array}{l}\text { Dummy variable that takes the value of } 1 \text { if the insurer has a stock own- } \\
\text { ership and } 0 \text { otherwise }\end{array}$ \\
\hline
\end{tabular}

${ }^{\text {a }}$ Premiums are expressed on an earned basis, i.e. reflecting the year in which the coverage was provided, regardless of the year in which the premium was paid. Losses are expressed on an incurred basis, i.e. reflecting the year in which the loss occurred, regardless of the year in which the claim was filed or paid

b'Ceding' in insurance is the transferring of all or part of a policy premium (and its associated losses) from the issuing insurer to a reinsurer or an insurer acting as a reinsurer. The reinsurer receiving this premium is said to be 'assuming' the premium (and its associated losses)

${ }^{\mathrm{c}}$ Total losses are all losses associated with policies issued directly by the insurer to policyholders

${ }^{\mathrm{d}}$ In non-proportional reinsurance contracts, the proportion of losses assumed by the reinsurer might be different from the proportion of premiums assumed by the reinsurer. In general, the proportion of losses assumed by the reinsurer in these contracts is an increasing function of the loss ratio

${ }^{\mathrm{e}}$ In proportional reinsurance contracts, the proportion of losses assumed by the reinsurer is equal to the proportion of premiums assumed by the reinsurer

${ }^{\mathrm{f}}$ Adjusted capital is the difference between the value of the assets and the value of the liabilities, as accounted for regulatory purposes. RBC capital is the minimum capital required by the insurance commissioner for the insurer to operate without intervention

where the maximum and average of the loss ratio are for the last 10 years. The key here is to define the look-back horizon for the maximum and the average. Lossbased CRE is a noisy measure of CAT risk exposure, and a longer window reduces the noise. However, we want a somewhat similar look-back period for each insurer so that the maximum represents a similar point in the distribution for each insurer. This means that a longer window reduces the size of the sample. There is a further complication. Because loss-based CRE is a noisy measure of CAT risk exposure, the coefficients on loss-based CRE in any regression will underestimate the effects of CAT risk exposure on reinsurance use (Griliches and Hausman 1986). This again points us towards a longer window. Given the available data, using 10 years of data provides a long exposure, reducing noise and bias, while allowing for a relatively large sample. Insurers with more than two years of missing data in the look-back 
period are excluded from the analysis. Our results are robust to modest changes in the look-back period. ${ }^{11}$

Loss-based CRE has a mean value of 1.46 during our sample period (Table 1). ${ }^{12}$ This means that the maximum loss over a 10 -year period is about $50 \%$ larger than the average loss over the same period. This can be compared to the average loss ratio of 54.3\%. Loss-based CRE has an important right tail, explained by large losses from natural catastrophes. This can also be seen in Fig. 1, where the average share of losses that are reinsured for insurers are plotted for two different groups of insurers in the years 2007-2018. Insurers with above-median loss-based CRE have substantially more variable losses than insurers with below-median loss-based CRE. Over the same period, the average share of premiums reinsured did not differ across the two groups (see Fig. 2).

We expect that CAT risk exposure will have a different effect on the use of quota reinsurance than it does on the use of non-proportional reinsurance. However, insurers are not required to report separately the premiums reinsured with quota and non-proportional contracts. This led previous studies to examine the effect of their measures of CAT risk exposure on total reinsurance use. In order to obtain a more accurate reflection of how insurers use reinsurance to reduce tail risk, we use past losses and reinsurance activity to derive estimates of quota and non-proportional reinsurance use.

The key to splitting reinsurance use into quota and non-proportional is to note that, for quota policies, reinsurance payments are a fixed proportion of losses. If an insurer cedes a fixed percentage of its premiums to a reinsurer, around the same percentage of its losses should be covered by the reinsurer. ${ }^{13}$ To go from this observation to a measure of the share of reinsurance that is non-proportional, we need to make two assumptions. The first is that, for an insurer, the split between quota and non-proportional reinsurance is stable over our look-back period (which is 10 years). ${ }^{14}$ The second assumption is that there is a 'non-CAT' year for the insurer over the look-back period. By this we mean a year when there are minimal payments from reinsurance to insurers on non-proportional reinsurance contracts. ${ }^{15,16}$ With these assumptions, the 'non-CAT' year for an insurer is the year in which the ratio of

\footnotetext{
11 Ideally, we would like to estimate our measure of CAT risk using the observed losses in a much longer time window, but our data start in 1996. This means that we might not be able to capture very low probability events, for example those that occur once in every 100 years. The findings are robust to using the largest historical loss ratio divided by the average loss ratio as the measure of CAT risk exposure.

12 Loss-based CRE is winsorised at the $1 \%$ level. The summary statistics reflect that.

13 There may be small differences if the reinsurer builds in a different margin of premium for profit than the insurer issuing the policy does.

14 The results are robust to assuming that the ratio is stable over three years, which is a much weaker assumption.

15 We don't have information from U.S. insurers (the ceding party) to test the stability of the share of non-proportional premiums reinsured. However, we have information from U.S.-based reinsurers (the assuming party), and in these data the share of non-proportional reinsurance is stable over time.

16 Empirical data supports the 'non-CAT' year assumption; even at the industry level the CAT losses in a low-CAT year such as 2007 are about 20 times smaller than the CAT losses in a high-CAT year such as 2005. At the insurer level, this ratio should be even more pronounced.
} 
losses ceded to total losses is at its minimum. In that year quota share, our estimated share of all premiums that are for quota reinsurance, is

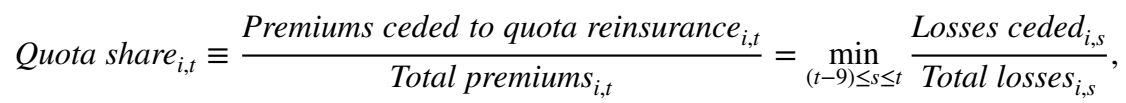

where the minimum is taken over the last 10 years for each insurer. ${ }^{17}$ It is straightforward to use quota share to estimate the share of all premiums that are for nonproportional reinsurance:

$$
\begin{aligned}
\text { Non-proportional share }_{i, t} \equiv & \frac{\text { Premiums ceded to non-proportional reinsurance }_{i, t}}{\text { Total premiums }_{i, t}} \\
& =\frac{\text { Premiums ceded to all reinsurance }_{i, t}}{\text { Total premiums }_{i, t}}-{\text { Quota } \text { share }_{i, t}}
\end{aligned}
$$

The intuition is that in a year in which the losses ceded to non-proportional reinsurance contracts are zero, the proportion of losses ceded are all attributable to proportional contracts. In addition, by construction the proportion of losses ceded to proportional reinsurance contracts is equal to the proportion of premiums ceded in this type of contract. Therefore, we can estimate the proportion of premiums ceded to proportional contracts as the proportion of losses ceded in a year in which nonproportional ceded losses are zero. Moreover, we work under the assumption that in a span of 10 years, we observe at least one year in which losses are small enough not to trigger protection from non-proportional contracts. The quality of our approximation deteriorates to the extent that this assumption does not hold, i.e. to the extent that there are non-proportional reinsurance payments even in small losses years.

Using this methodology, we find that that roughly one third of all reinsurance premiums are used for non-proportional reinsurance $(10.2 \%$ is ceded using non-proportional reinsurance contracts, while $22 \%$ of premiums are ceded using proportional reinsurance contracts; see Table 1). The use of reinsurance, both in total and for the different types, varies significantly across insurers, with some having minimal reinsurance and others having most premiums reinsured. For example, insurers in the 25 th percentile in terms of the use of reinsurance cede only $15.6 \%$ of their premiums, while those in the 75 th percentile cede $47.5 \%$ of their premiums. Losses ceded - payments from reinsurers - present even greater variation compared with premiums ceded, as seen in the summary statistics. The difference in the amount of variation is consistent with reinsurers protecting against tail risk. If reinsurers provide tail risk protection, the proportion of losses ceded will increase when losses are larger, even when the proportion of premiums ceded remains constant.

The next step in our analysis is to examine how reinsurance use depends on insurers' exposure to CAT risk and other insurer characteristics. We estimate the

\footnotetext{
17 This will overestimate the quota reinsurance to the extent that some non-proportional contracts still cover insurance losses in the year with the minimum ratio of ceded losses to losses.
} 


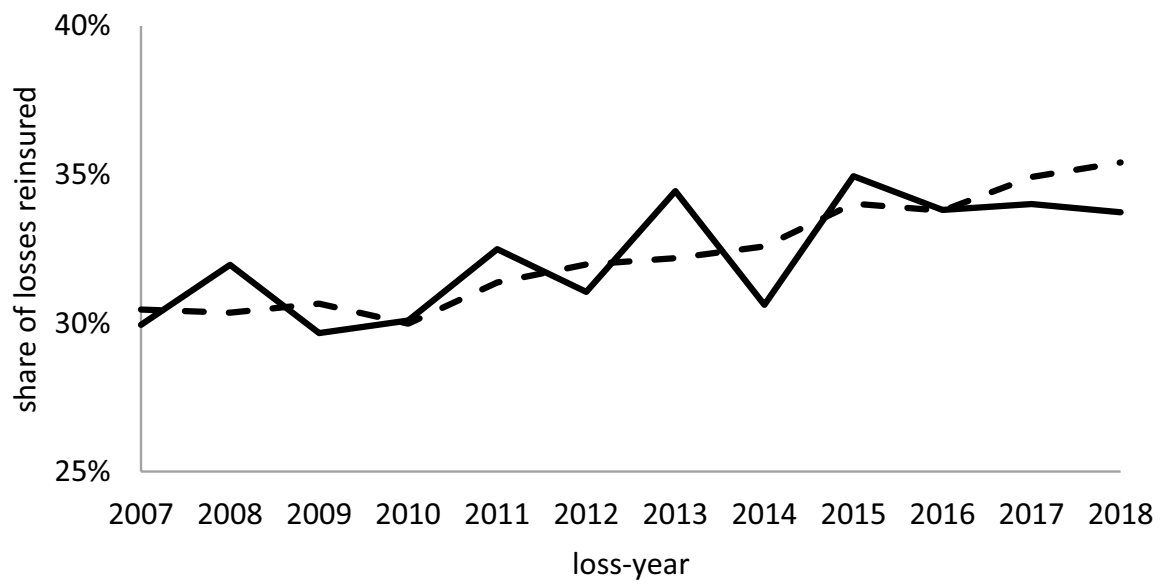

- below-median loss-based CRE

above-median loss-based CRE

Fig. 1 Share of losses reinsured by year. This figure presents the average share of losses reinsured by insurers from 2007 to 2018. The sample is divided into two subsamples: insurers with above-median loss-based CRE and insurers with below-median loss-based CRE, where loss-based CRE is estimated as of 2007, i.e. the maximum loss ratio between 1997 and 2006 divided by the mean loss ratio within the same timeframe. Insurers for whom the ratio of premiums assumed from other insurers (i.e. insurance provided to other insurers) to the insurance provided directly to policyholders is larger than $20 \%$ are considered reinsurers and are excluded from the calculations

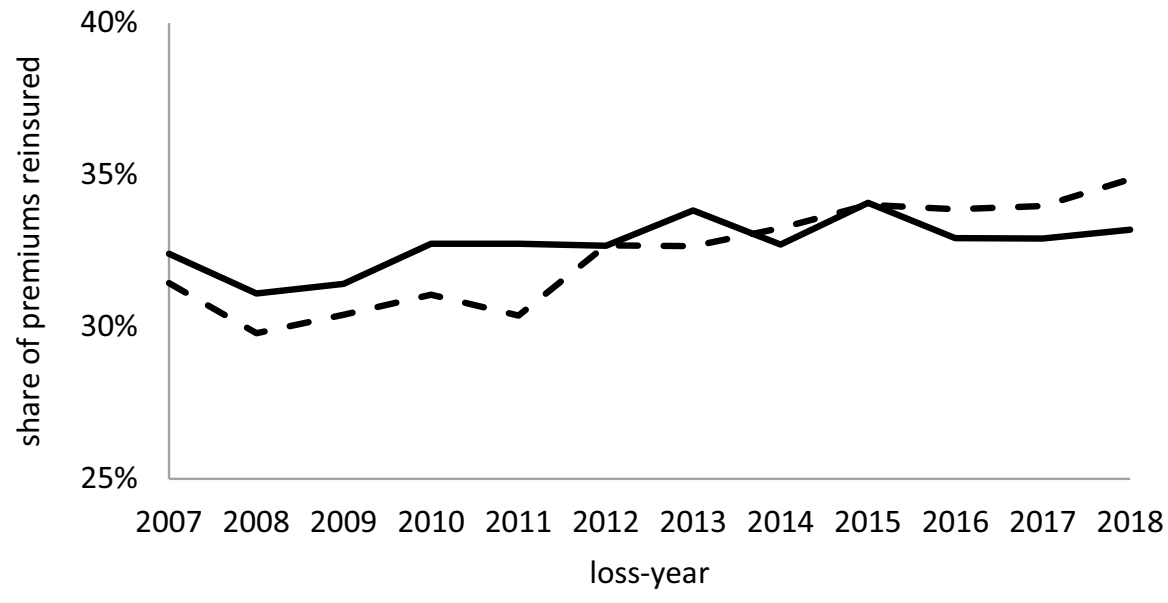

- below-median loss-based CRE

above-median loss-based CRE

Fig. 2 Share of premiums reinsured by year. This figure presents the average share of premiums reinsured by insurers from 2007 to 2018. The sample is divided into 2 subsamples: insurers with abovemedian loss-based CRE and insurers with below-median loss-based CRE, where loss-based CRE is estimated as of 2007, i.e. the maximum loss ratio between 1997 and 2006 divided by the mean loss ratio within the same timeframe. Insurers for whom the ratio of premiums assumed from other insurers (i.e. insurance provided to other insurers) to the insurance provided directly to policyholders is larger than $20 \%$ are considered reinsurers and are excluded from the calculations 
relationship between the reinsurance shares and CAT risk for total reinsurance, quota reinsurance and non-proportional reinsurance using

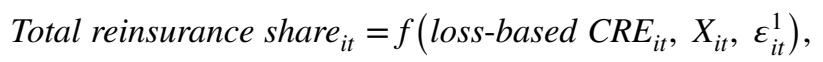

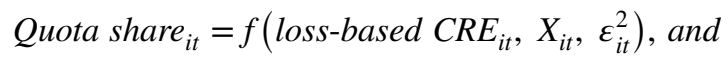

$$
\text { Non-proportional } \text { share }_{i t}=f\left(\text { loss-based } C R E_{i t}, \boldsymbol{X}_{i t}, \varepsilon_{i t}^{3}\right) \text {, }
$$

where total reinsurance share $=$ quota share + non-proportional share; loss-based $C R E$ is our CAT risk measure as given by (1); $\boldsymbol{X}_{k}$ is a set of variables that capture risk (selected based on previous studies) plus additional controls that might affect the use of reinsurance; and $\varepsilon_{i t}^{e}$ are i.i.d. error terms. To reduce concerns about endogeneity, all the variables are as for year $t-1$, except for the dependent variable that is as for year $t$. We use a Tobit-censored regression with lower limit at 0 and upper limit at 1 to measure the correlation between the reinsurance shares and the explanatory variables. ${ }^{18}$ Standard errors are clustered at the insurer level and are robust to heteroscedasticity. We report the $F$-test for the significance of the coefficients. $\mathrm{R}^{2}$ is unavailable for Tobit-censored estimation.

There are other reasons why insurers might use reinsurance. We want to control for these to minimise any omitted variable bias. Insurers might use reinsurance to manage capital. Regulators do not require insurers to hold capital against reinsured premiums. ${ }^{19}$ This means that low-capital insurers might be able to increase their regulatory capital ratios or expand their business by using more reinsurance. We control for this using an insurer's regulatory $\mathrm{RBC}$ ratio. The $\mathrm{RBC}$ ratio is the ratio of adjusted capital to risk-based capital, where adjusted capital is the difference between the value of the assets and the value of liabilities, as accounted for regulatory purposes, and risk-based capital is the minimum capital required by the regulator for an insurer to operate without regulatory intervention given its risk exposure. ${ }^{20}$ The RBC ratio varies greatly across insurers, mostly because some insurers have adjusted capital orders of magnitude above what is required by regulators. The average $\mathrm{RBC}$ ratio is $10.32(1032 \%)$ with an interquartile range between 6.64 (or $664 \%$ ) and 12.66 (or $1266 \%)^{21}$

\footnotetext{
18 We use a censored regression because insurers cannot take negative reinsurance or reinsurance above $100 \%$, even if they may wish to do so.

19 Technically, insurers are not required to hold capital against what is known as authorised reinsurance. In our sample, less than $1 \%$ of reinsurance is either unauthorised or a 'mixed filing'. The results are unchanged from restricting the sample to authorised reinsurance.

20 The minimum amount of capital required by the state regulator for the insurer to operate without regulatory intervention is based on the RBC ratio. When the RBC ratio falls below $200 \%$, the insurer needs to submit a capital plan to be approved by the state insurance commissioner. When the RBC ratio falls below $100 \%$, the regulator has the option of taking control of the insurer and when the ratio is below $70 \%$, the regulator is required to place the insurer under control.

21 The $\mathrm{RBC}$ ratio is winsorised at the $1 \%$ level. The summary statistics reflect this.
} 
While we use the RBC ratio as our primary measure of low capital, almost all the insurers in our sample have significantly more than the regulatory minimum level of capital. This may be because insurers also care about their ratings from rating agencies. For this reason, we also control for ratings using the AM Best risk rating. There are 15 AM Best rating categories; for the statistical analysis, each category is assigned a numerical value from 1 to 15 , where 1 represents the safest insurers $(\mathrm{A}++)$ and 15 represents the riskiest insurers $(\mathrm{F}) .^{22}$ The rating for an insurance group is the asset-weighted average rating of all the affiliated companies (rounded to the closest integer).

The average rating is 3.81, which is roughly an A-rating. When an AM Best rating decreases, especially to a rating below A, insurers can have problems such as lower premium growth (Epermanis and Harrington 2006). We use three AM Best rating dummies: $A M B$ high $=1$ for insurers with a rating of $\mathrm{A}$ or better, $A M B$ medium $=1$ for insurers with a rating of $\mathrm{A}-$, and $A M B$ low $=1$ for insurers with a rating below A-.

For completeness, we also include the leverage ratio, the ratio of premiums to adjusted capital and profitability, since they have been used in other studies (e.g. Garven and Lamm-Tennant 2003; Park et al. forthcoming). Leverage is defined as liabilities divided by adjusted capital and profitability is measured by the pre-tax return on assets (ROA). ${ }^{23}$

Finally, we add dummies to indicate whether the observation corresponds to a group of insurers under the same ownership (i.e. not standalone) and whether it is a stock company, as well as year fixed effects to control for time trends. A list of the variables used in the study is provided in Panel B of Table 1.

\section{Results}

This section shows how reinsurance use is related to CAT risk exposure. On the surface, insurers more exposed to CAT risk use more reinsurance, especially nonproportional. Table 2 presents the average use of reinsurance by insurers as a function of CAT risk, as measured by loss-based CRE. The overall use of reinsurance increases somewhat as loss-based CRE increases, but high loss-based CRE insurers use substantially more non-proportional reinsurance. Insurers in the highest lossbased CRE quartile use well over twice as much non-proportional reinsurance as insurers in either of the two lowest quartiles.

To determine whether the patterns in Table 2 are driven by our measure of CAT risk exposure and not by other characteristics of the insurers or their location, we estimate specifications (2)-(4). We start by examining the effect of CAT risk on total reinsurance to parallel the prior literature. The first column of results in Table 3 reports the results of the regression of total reinsurance use against the CAT risk

\footnotetext{
${ }^{22}$ The list of $\mathrm{AM}$ Best categorical risk ratings (from safest to riskiest) is: $\mathrm{A}++, \mathrm{A}+, \mathrm{A}, \mathrm{A}-, \mathrm{B}++, \mathrm{B}+, \mathrm{B}$, B-, C++, C+, C, C-, D, E, F.

${ }^{23}$ Leverage and ROA are winsorised at the $1 \%$ level. The summary statistics reflect this.
}

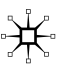


exposure measures and year dummies. Having more CAT risk exposure, as measured by loss-based CRE, significantly increases an insurer's use of reinsurance. The coefficients on geographic CRE, geographic Herf and business line Herf are consistent with prior studies. Adding additional control variables, as reported in column 2 of Table 3, does not change the coefficient on loss-based CRE appreciably, but reduces the magnitudes and significance of the coefficients on geographic CRE, geographic Herf and business line Herf.

The remainder of Table 3 reports results using our breakdown of reinsurance into non-proportional (column 3) and quota (column 4) with the full set of controls. The factors associated with the use of non-proportional reinsurance are different from those associated with the use of quota reinsurance.

Having more loss-based CRE significantly increases an insurer's use of non-proportional reinsurance but has essentially no effect on its use of quota reinsurance. The effect of this measure of CAT risk exposure on non-proportional reinsurance usage is economically significant as well. A one standard deviation increase in loss-based $C R E$ (0.48) predicts a 3\% increase in the share of premiums ceded for non-proportional reinsurance. ${ }^{24}$ This is one third of the average share of premiums ceded for nonproportional reinsurance. The coefficient on loss-based CRE in the quota reinsurance regression is small ( 0.011 compared to 0.062 in the non-proportional regression), suggesting that CAT risk exposure is not a major factor in decisions on quota reinsurance.

The coefficients on the measures of CAT risk exposure used in the prior literature are interesting. Geographic CRE has some predictive power for the use of quota reinsurance but not for non-proportional reinsurance. The coefficients on geographic Herf and business line Herf are both negative, although only the coefficient on geographic Herf is significantly different from zero. The negative signs are consistent with the hypothesis that insurers use reinsurance at least in part because of the information reinsurers provide, as opposed to using it just to reduce undiversified risk (Mayers and Smith 1990). The more concentrated an insurer is, the more likely it is to know about its lines of business (for business line Herf) or local markets (for geographic Herf). We discuss possible explanations for the coefficients on geographic $C R E$ after we finish presenting the regression results in Table 3.

We also examine the use of reinsurance for capital management. Since insurers do not have to hold regulatory capital for the part of a policy that is reinsured, reinsurance can allow insurers to grow without raising new capital. To test this, we add risk-based capital dummies to the regressions with CAT risk exposure controls. We divide insurers into quartiles by their RBC ratios after accounting for the effect of reinsurance. Low $R B C$ ratio is 1 for insurers in the lowest quartile, $Q 2 R B C$ ratio is 1 for insurers in the second-lowest $\mathrm{RBC}$ quartile and $Q 3 \mathrm{RBC}$ ratio is 1 for insurers in the second-highest RBC quartile (so high-RBC insurers are the excluded group). Insurers in the two low capital quartiles use significantly more quota reinsurance but no more non-proportional reinsurance, consistent with the use of reinsurance for

\footnotetext{
${ }^{24}$ Recall that the coefficients on loss-based CRE underestimate the marginal effect of true CAT risk exposure on reinsurance use. Our estimates (not shown) suggest that the underestimation is of the order of $10 \%$.
} 
Table 2 Reinsurance used by loss-based CRE quartile

\begin{tabular}{llll}
\hline Loss-based CRE quartile & $\begin{array}{l}\text { Total reinsurance share } \\
(\%)\end{array}$ & $\begin{array}{l}\text { Non-proportional share } \\
(\%)\end{array}$ & Quota share (\%) \\
\hline Top quartile & 34.1 & 15.5 & 18.6 \\
Second quartile & 32.1 & 11.5 & 20.6 \\
Third quartile & 32.1 & 7.8 & 24.4 \\
Bottom quartile & 31.8 & 6.1 & 25.7 \\
\hline
\end{tabular}

This table presents the average total reinsurance share, non-proportional share and quota share between 2007 and 2018 for insurers in each quartile of loss-based CRE. Quartiles are estimated using the lossbased CRE in 2007, i.e. the max loss ratio between 1997 and 2006 divided by the mean loss ratio within the same timeframe. The top quartile has the highest average loss-based CRE and the bottom quartile has the lowest average loss-based CRE

capital management. The effects are large: all else being equal, a low-RBC insurer has a $10.8 \%$ higher share of quota reinsurance than a high-RBC insurer. Insurers in the second-lowest $\mathrm{RBC}$ quartile also use significantly more quota reinsurance than high-RBC insurers. These results are consistent with evidence provided by practitioners and regulators showing that reinsurers offer proportional reinsurance products specifically tailored to address regulatory capital constraints (Zhou-Richter and Kuschel 2012; Wertli 2016; Troutman 2011; Lum 2013). ${ }^{25}$ The leverage ratio has no significant effect on reinsurance once the RBC ratio is controlled for. This suggests that insurers may manage leverage risk using the $\mathrm{RBC}$ ratio rather than the simple leverage ratio.

We also include asset size and controls for the corporate organisation of the insurer in the regressions. Not surprisingly, larger insurers and (weakly) group members use less non-proportional reinsurance, consistent with those insurers having a greater ability to diversify.

The other controls are generally insignificant. The AM Best rating of an insurer does not affect its use of reinsurance, nor does the ROA or leverage. The coefficient on the ratio of premiums to adjusted capital is significantly positive at the $10 \%$ level and higher values of the ratio indicate increased use of reinsurance, especially quota reinsurance.

As noted earlier, one surprising result is that geographic CRE is a significant predictor of quota reinsurance use but not of non-proportional reinsurance use. The insignificant coefficient on geographic CRE in the non-proportional regression may arise because geographic $C R E$ is a very coarse variable. It measures hurricane exposure by aggregating premiums from states on the Atlantic and Gulf coasts and then adds in California earthquake premiums. The degree of exposure to hurricanes varies widely across the Atlantic and Gulf coast states. For example, almost all of Florida is hit by hurricanes but only part of New York has significant hurricane risk. To see whether the coarseness of the geographic

${ }^{25}$ To the extent that the use of reinsurance affects capital ratios, it should reduce the coefficients on the RBC dummies that we estimate. 
Table 3 Proportion of premiums ceded

\begin{tabular}{|c|c|c|c|c|}
\hline \multirow[t]{2}{*}{ Dependent variable } & (1) & (2) & \multirow{2}{*}{$\begin{array}{l}\text { (3) } \\
\text { Non-proportional share }\end{array}$} & \multirow{2}{*}{$\begin{array}{l}\text { (4) } \\
\text { Quota share }\end{array}$} \\
\hline & \multicolumn{2}{|c|}{ Total reinsurance share } & & \\
\hline \multirow[t]{2}{*}{ Loss-based CRE } & $0.062 * * *$ & $0.076^{* * *}$ & $0.062 * * *$ & 0.011 \\
\hline & $(0.018)$ & $(0.017)$ & $(0.010)$ & $(0.017)$ \\
\hline \multirow[t]{2}{*}{ Geographic CRE } & $0.057 * *$ & $0.042 *$ & 0.003 & $0.047 * *$ \\
\hline & $(0.024)$ & $(0.023)$ & $(0.011)$ & $(0.023)$ \\
\hline \multirow[t]{2}{*}{ Geographic Herf } & $-0.136^{* * *}$ & $-0.070^{* *}$ & $-0.029 * *$ & -0.042 \\
\hline & $(0.026)$ & $(0.029)$ & $(0.013)$ & $(0.029)$ \\
\hline \multirow[t]{2}{*}{ Business line Herf } & $-0.129 * * *$ & -0.046 & -0.019 & -0.044 \\
\hline & $(0.038)$ & $(0.038)$ & $(0.018)$ & $(0.040)$ \\
\hline \multirow[t]{2}{*}{ Low $\mathrm{RBC}$ ratio } & $0.107 * * *$ & $0.113 * * *$ & 0.003 & $0.108 * * *$ \\
\hline & $(0.036)$ & $(0.036)$ & $(0.017)$ & $(0.037)$ \\
\hline \multirow[t]{2}{*}{ Q2 RBC ratio } & $0.075 * * *$ & $0.067 * * *$ & -0.008 & $0.076^{* * *} *$ \\
\hline & $(0.023)$ & $(0.024)$ & $(0.010)$ & $(0.023)$ \\
\hline \multirow[t]{2}{*}{ Q3 RBC ratio } & 0.022 & 0.010 & -0.006 & 0.016 \\
\hline & $(0.019)$ & $(0.018)$ & $(0.008)$ & $(0.018)$ \\
\hline \multirow[t]{2}{*}{ AMB medium } & & 0.013 & 0.005 & 0.011 \\
\hline & & $(0.023)$ & $(0.011)$ & $(0.023)$ \\
\hline \multirow[t]{2}{*}{ AMB high } & & 0.004 & 0.005 & 0.002 \\
\hline & & $(0.028)$ & $(0.012)$ & $(0.028)$ \\
\hline \multirow[t]{2}{*}{ Return on assets } & -0.010 & 0.004 & -0.028 & 0.020 \\
\hline & $(0.058)$ & $(0.057)$ & $(0.029)$ & $(0.055)$ \\
\hline \multirow[t]{2}{*}{ Leverage } & -0.008 & -0.025 & 0.001 & -0.024 \\
\hline & $(0.017)$ & $(0.017)$ & $(0.007)$ & $(0.018)$ \\
\hline \multirow[t]{2}{*}{ Premiums/adjusted capital } & 0.013 & $0.033^{*}$ & -0.001 & $0.036^{*}$ \\
\hline & $(0.017)$ & $(0.018)$ & $(0.007)$ & $(0.019)$ \\
\hline \multirow[t]{2}{*}{ Log assets } & & 0.009 & $-0.016 * * *$ & $0.026^{* * *} *$ \\
\hline & & $(0.008)$ & $(0.003)$ & $(0.009)$ \\
\hline \multirow[t]{2}{*}{ Insurer is part of a group } & & $0.106^{* * *}$ & -0.006 & $0.123 * * *$ \\
\hline & & $(0.027)$ & $(0.012)$ & $(0.027)$ \\
\hline \multirow[t]{2}{*}{ Stock company } & & -0.001 & 0.013 & -0.026 \\
\hline & & $(0.020)$ & $(0.009)$ & $(0.021)$ \\
\hline Observations & 3233 & 3233 & 3233 & 3233 \\
\hline$F$-test & 6.221 & 7.702 & 7.562 & 9.580 \\
\hline
\end{tabular}

This table presents a Tobit-censored regression with lower limit at 0 and upper limit at 1 of the amount of reinsurance: total reinsurance share, non-proportional share and quota share as a function of a set of firm characteristics and risk exposures. All of the variables are as for year $t-1$, except for the dependent variable that is as for year $t$. The sample period is 2007 to 2018

All estimations have year effects. Robust standard errors are in parentheses and statistical significance is denoted by $* * * p<0.01, * * p<0.05, * p<0.1$

$C R E$ proxy matters, we divide geographic $C R E$ into its constituent states. For California, the geographic CRE measure includes only earthquake insurance, 
Table 4 Proportion of premiums ceded breaking out regional exposure

\begin{tabular}{|c|c|c|}
\hline Variable & $\begin{array}{l}\text { (1) } \\
\text { Non-proportional share }\end{array}$ & $\begin{array}{l}\text { (2) } \\
\text { Quota share }\end{array}$ \\
\hline Florida & $\begin{array}{l}0.126 * * * \\
(0.038)\end{array}$ & $\begin{array}{l}0.002 \\
(0.051)\end{array}$ \\
\hline Alabama & $\begin{array}{l}-0.017 \\
(0.046)\end{array}$ & $\begin{array}{l}0.171 \\
(0.162)\end{array}$ \\
\hline Mississippi & $\begin{array}{l}-0.246^{*} \\
(0.130)\end{array}$ & $\begin{array}{l}-0.179 \\
(0.212)\end{array}$ \\
\hline Louisiana & $\begin{array}{l}-0.055^{* * * *} \\
(0.021)\end{array}$ & $\begin{array}{l}0.006 \\
(0.095)\end{array}$ \\
\hline Georgia & $\begin{array}{l}-0.028 \\
(0.025)\end{array}$ & $\begin{array}{l}-0.098 \\
(0.072)\end{array}$ \\
\hline South Carolina & $\begin{array}{l}0.019 \\
(0.049)\end{array}$ & $\begin{array}{l}0.289 * * * \\
(0.054)\end{array}$ \\
\hline North Carolina & $\begin{array}{l}0.032 \\
(0.029)\end{array}$ & $\begin{array}{l}-0.019 \\
(0.100)\end{array}$ \\
\hline Virginia & $\begin{array}{l}0.030 \\
(0.068)\end{array}$ & $\begin{array}{l}0.056 \\
(0.077)\end{array}$ \\
\hline District of Columbia & $\begin{array}{l}-0.061 \\
(0.196)\end{array}$ & $\begin{array}{l}0.180 \\
(0.324)\end{array}$ \\
\hline Maryland & $\begin{array}{l}-0.047 \\
(0.033)\end{array}$ & $\begin{array}{l}-0.088^{*} \\
(0.050)\end{array}$ \\
\hline Delaware & $\begin{array}{l}-0.517 * * \\
(0.228)\end{array}$ & $\begin{array}{l}1.267 * \\
(0.758)\end{array}$ \\
\hline New Jersey & $\begin{array}{l}0.007 \\
(0.034)\end{array}$ & $\begin{array}{l}0.026 \\
(0.056)\end{array}$ \\
\hline New York & $\begin{array}{l}-0.019 \\
(0.013)\end{array}$ & $\begin{array}{l}0.133 * * * \\
(0.039)\end{array}$ \\
\hline Connecticut & $\begin{array}{l}0.113 * * * \\
(0.036)\end{array}$ & $\begin{array}{l}-0.071 \\
(0.163)\end{array}$ \\
\hline Rhode Island & $\begin{array}{l}0.101 \\
(0.094)\end{array}$ & $\begin{array}{l}-0.199 \\
(0.533)\end{array}$ \\
\hline Massachusetts & $\begin{array}{l}-0.006 \\
(0.028)\end{array}$ & $\begin{array}{l}0.069 \\
(0.049)\end{array}$ \\
\hline New Hampshire & $\begin{array}{l}-0.263^{* * * *} \\
(0.098)\end{array}$ & $\begin{array}{l}-0.259 \\
(0.265)\end{array}$ \\
\hline Maine & $\begin{array}{l}0.131 * * \\
(0.062)\end{array}$ & $\begin{array}{l}0.058 \\
(0.139)\end{array}$ \\
\hline California earthquake & $\begin{array}{l}-0.060 \\
(0.168)\end{array}$ & $\begin{array}{l}0.851^{*} \\
(0.496)\end{array}$ \\
\hline California non-earthquake & $\begin{array}{l}-0.032^{* *} \\
(0.014)\end{array}$ & $\begin{array}{l}0.057 \\
(0.046)\end{array}$ \\
\hline Observations & 3151 & 3151 \\
\hline$F$-test & 5.520 & 8.945 \\
\hline
\end{tabular}


Table 4 (continued)

This table presents regressions similar to those in columns (3) and (4) of Table 3, with the addition of the share of premiums in each constituent state. Earthquake and non-earthquake $\mathrm{P} \& \mathrm{C}$ premiums are reported separately for California. All control variables from Table 3 are included; however, only the coefficients on the state premium shares are reported. All of the variables are as for year $t-1$, except for the dependent variable that is as for year $t$. The sample period is 2007 to 2018 . All estimations have year fixed effects

Robust standard errors are in parentheses and statistical significance is denoted by $* * * p<0.01, * * p<0.05, * p<0.1$

so we include a separate variable for California non-earthquake $\mathrm{P} \& \mathrm{C}$ premiums. Table 4 reports the coefficients on the state-specific variables from regressions similar to those in columns 3 and 4 of Table 3, but with geographic CRE replaced by the individual state measures (plus California non-earthquake). The set of control variables included in Table 4 is the same as in Table 3 , and all the coefficients on these control variables are similar in magnitude and statistical significance to the coefficients reported in Table 3. For brevity, these coefficients are not reported in Table 4.

The state-by-state exposure measures show the difficulty of disaggregating to the state level. Of those states, Florida is the state with the widest exposure to CAT risk. Thus, it is not surprising that exposure to Florida is associated with higher non-proportional reinsurance. However, it is somewhat surprising that the only coefficients on the other Gulf and Atlantic state variables in the non-proportional regression that are significantly positive are Connecticut and Maine, two states with minimal CAT exposure relative to the other states in geographic $C R E$. In fact, Mississippi, a state that has been hit by hurricanes relatively frequently, has a negative coefficient. This suggests that there may be state-specific reasons that affect the use of reinsurance. The coefficients in the quota reinsurance regression have a wide range, from significantly positive and large to significantly negative, providing some support for this explanation.

It seems surprising that exposure to California earthquake, an important source of CAT risk, is not associated with a higher use of non-proportional reinsurance. However, the California Earthquake Authority provides most of the earthquake insurance in California, and private insurers only act as intermediaries between the authority and the policyholders.

These results show that where there is clear exposure to CAT risk, insurers appear to use more reinsurance. However, the geographic CAT risk exposure measure used in the prior literature may be too coarse to select mostly insurers that are heavily exposed to CAT risk. One possibility would be to focus on more specific areas - for example, Florida - where most, if not all, insurers are quite exposed to CAT risk. The risk of this is that, as shown in Table 4, there are differences in the use of non-proportional and quota reinsurance across states that are not explained by our set of controls. These state-specific motivations for the use of reinsurance could include such things as elements of the regulatory 
environment. This suggests that narrowing the geographic spread of a CAT risk exposure measure too much risks picking up idiosyncratic motivations for the use of reinsurance. The loss-based CRE measure we propose is largely orthogonal to these state-specific effects.

\section{Conclusion}

Existing academic work indicates that catastrophe risk is an important driver of reinsurance use. However, due to limited availability of contractual information, the extent to which additional reinsurance comes in the form of quota contracts or nonproportional contracts remained an open question. In this paper, we make two methodological contributions. First, we develop a measure of the share of reinsurance that is non-proportional. Our measures imply that approximately one third of reinsurance is non-proportional, consistent with other estimates. Our second contribution is to construct a novel measure of CAT risk that relies on past losses. This new measure has a strong explanatory power as a determinant of the use of reinsurance, even after controlling for an exhaustive list of variables historically used to explain demand for reinsurance.

We use our two new measures to answer the open question of how the different types of reinsurance - quota and non-proportional - are used. We find that reinsurance use goes up with exposure to CAT risk and that this is due to an increase in non-proportional reinsurance. We find no evidence that quota reinsurance usage is higher at insurers with greater CAT risk exposure.

The new tools we develop in this paper can be used by practitioners and regulators alike to evaluate the use of reinsurance in different setups. They can help the understanding of how insurers use reinsurance to help cope with the financial burden associated with large catastrophe losses. This may become increasingly important if the areas exposed to CAT risk and the destruction caused by catastrophic events evolve over time because of climate change.

Open Access This article is licensed under a Creative Commons Attribution 4.0 International License, which permits use, sharing, adaptation, distribution and reproduction in any medium or format, as long as you give appropriate credit to the original author(s) and the source, provide a link to the Creative Commons licence, and indicate if changes were made. The images or other third party material in this article are included in the article's Creative Commons licence, unless indicated otherwise in a credit line to the material. If material is not included in the article's Creative Commons licence and your intended use is not permitted by statutory regulation or exceeds the permitted use, you will need to obtain permission directly from the copyright holder. To view a copy of this licence, visit http://creativecommons.org/licen ses/by/4.0/.

\section{References}

Borch, K. 1962. Equilibrium in a reinsurance market. Econometrica 30: 424-444.

Borch, K. 1961. The utility concept applied to the theory of insurance. ASTIN Bulletin: The Journal of the IAA 1: 245-255. 
Cummins, J.D., N. Doherty, and A. Lo. 2002. Can insurers pay for the "big one"? Measuring the capacity of the insurance market to respond to catastrophic losses. Journal of Banking \& Finance 26: 557-583.

Doherty, N.A., and H. Schlesinger. 1983. Optimal insurance in incomplete markets. Journal of Political Economy 91 (6): 1045-1054.

Drexler, A., and F. Eloundou Nekoul. 2016. Do insurers in catastrophe-prone regions buy enough reinsurance? Chicago Fed Letter.

Engeström, J. 1995. Impact of catastrophes on the reinsurance industry. The Geneva Papers on Risk and Insurance-Issues and Practice 20: 463-473.

Epermanis, K., and S.E. Harrington. 2006. Market discipline in property/casualty insurance: evidence from premium growth surrounding changes in financial strength ratings. Journal of Money, Credit and Banking 38 (6): 1515-1544.

Froot, K.A. 2001. The market for catastrophe risk: a clinical examination. Journal of Financial Economics 2-3: 529-571.

Garven, J.R., and J. Lamm-Tennant. 2003. The demand for reinsurance: theory and empirical tests. Insurance and Risk Management 7 (3): 217-237.

Griliches, Z., and J.A. Hausman. 1986. Errors in variables in panel data. Journal of Econometrics 31: 93-118.

Huang, H.-H. 2006. Optimal insurance contract under a value-at-risk constraint. The Geneva Risk and Insurance Review 31 (2): 91-110.

Koijen, R.S.J., and M. Yogo. 2016. Shadow insurance. Econometrica 84: 1265-1287.

Lum, D. 2013. Utilizing reinsurance for capital management. RMA Newsletter 2-3.

Manka1, S., and A. Belgacem. 2016. Interactions between risk taking, capital, and reinsurance for property-liability insurance firms. The Journal of Risk and Insurance 83 (4): 1007-1043.

Mayers, D., and C. Smith. 1990. On the corporate demand for insurance: evidence from the reinsurance market. The Journal of Business 63: 19-40.

Mohey-Deen, Z., and R. Rosen. 2018. The risks of pricing new insurance products: the case of long-term care. Chicago Fed Letter. https://doi.org/10.21033/cfl-2018-397.

Munich Re. 2017. Natural catastrophes 2016 analyses, assessments, positions. TOPICS GEO, p. 56.

Park, S.C., and X. Xie. 2014. Reinsurance and systemic risk: the impact of reinsurer downgrading on property-casualty insurers. The Journal of Risk and Insurance 81 (3): 587-621.

Park, S.C., X. Xie, and P. Rui. The sensitivity of reinsurance demand to counterparty risk: evidence from the U.S. property-liability insurance industry. The Journal of Risk and Insurance, forthcoming.

Polacek, A. 2015. How do property and casualty insurers manage risk? The role of reinsurance. Chicago Fed Letter.

Powell, L.S., and D.W. Sommer. 2007. Internal versus external capital markets in the insurance industry: the role of reinsurance. Journal of Financial Services Research 31: 173-188.

Raviv, A. 1979. The design of an optimal insurance policy. The American Economic Review 69 (1): 84-96.

Troutman, M. 2011. Quota share reinsurance solutions for risk-based capital relief. Society of Actuaries Reinsurance News, 70: 11-14.

Vajda, S. 1962. Minimum variance reinsurance. The Astin Bulletin 2 (2): 257-260.

Wang, C.-P., D. Shyu, and H.-H. Huang. 2005. Optimal insurance design under a value-at-risk framework. The Geneva Risk and Insurance Review 30 (2): 161-179.

Wang, J.L., V.Y. Chang, G.C. Lai, and L.Y. Tzeng. 2008. Demutualization and demand for reinsurance. The Geneva Papers on Risk and Insurance-Issues and Practice 33: 566-584.

Wertli, C. 2016. Effective solutions for improving solvency. Swiss Re Publication.

Zhou-Richter, T., and N. Kuschel. 2012. Cost of capital under Solvency II Reinsurance and capital market instruments. Munich Re Publications.

Publisher's Note Springer Nature remains neutral with regard to jurisdictional claims in published maps and institutional affiliations. 


\section{About the authors}

Alejandro Drexler is part of the Chicago Fed's Insurance Initiative. He works on insurance issues of interest to the Federal Reserve System in its roles as a central bank and as a regulator of systemically important financial institutions. Prior to coming to the Chicago Fed, Drexler taught in the finance department at the University of Texas at Austin. He has also worked for the Chilean Central Bank, the Chilean Department of Commerce, the World Bank and the Inter-American Bank for Development. Drexler has published in numerous leading academic journals including American Economic Journal, Management Science, Journal of Financial and Quantitative Analysis, Journal of Economic Behavior \& Organizations and Journal of Banking \& Finance.

Richard J. Rosen is a vice president at the Federal Reserve Bank of Chicago. He leads the Chicago Fed's Insurance Initiative which conducts research on insurance and provides expertise on the insurance industry within the Federal Reserve System. Rosen also conducts research on financial intermediation, bank regulation, mergers and housing. Rosen's research is published in numerous leading academic journals including: Journal of Finance, the Journal of Financial Economics, the Journal of Business, the Journal of Money, Credit and Banking and the Rand Journal. 